\title{
Distribution of Heavy Metals in the Soils Associated with the Commonly Used Pesticides in Cotton Fields
}

\author{
Saadia Rashid Tariq, ${ }^{1}$ Musharaf Shafiq, ${ }^{1}$ and Ghayoor Abbas Chotana ${ }^{2}$ \\ ${ }^{1}$ Department of Chemistry, Lahore College for Women University, Lahore 54000, Pakistan \\ ${ }^{2}$ Department of Chemistry, Syed Babar Ali School of Science \& Engineering, LUMS, Lahore 54792, Pakistan \\ Correspondence should be addressed to Saadia Rashid Tariq; saadiarashid74@gmail.com
}

Received 3 December 2015; Revised 10 February 2016; Accepted 11 February 2016

Academic Editor: Zeng-Yei Hseu

Copyright (c) 2016 Saadia Rashid Tariq et al. This is an open access article distributed under the Creative Commons Attribution License, which permits unrestricted use, distribution, and reproduction in any medium, provided the original work is properly cited.

\begin{abstract}
Agricultural soils contain both heavy metals and pesticides originating from various agricultural practices. It is quite important to study the relationships between these two classes of compounds. To accomplish this, 52 soil samples were collected from cotton fields and analyzed for their metal contents ( $\mathrm{Ni}, \mathrm{Cu}, \mathrm{Co}, \mathrm{Pb}, \mathrm{Cr}$, and $\mathrm{Cd}$ ) and levels of most commonly used pesticides (imidacloprid, acetamiprid, and emamectin). FAAS was used for metal estimation and the pesticides were determined by HPLC equipped with UV detector. The results of the study revealed slightly enhanced levels of $\mathrm{Ni}$ and $\mathrm{Cd}$ in these samples while the rest of the metals were present within tolerable range. Acetamiprid residues in soil were strongly positively correlated with $\mathrm{Cu}$ and negatively correlated with Cr. Similarly, imidacloprid in soil was negatively correlated with Ni. Thus it was evidenced that Cu stabilizes acetamiprid while $\mathrm{Cr}$ and $\mathrm{Ni}$ facilitate the degradation of acetamiprid and imidacloprid in the soil.
\end{abstract}

\section{Introduction}

Pesticides and heavy metals are the most hazardous contaminants of agricultural soils. In fact, the agricultural sustainability has long been associated with the use of a broad spectrum of pesticides that control the disease causing pests and crop destroying insects [1]. According to an estimate, in Pakistan alone about 20379 metric tons of pesticides is used annually with about $75 \%$ of these being used only for cotton crops [2]. That is why cotton fields have been found to be more contaminated than other modes of land use [3]. A significant portion of these pesticides (about 19\%) find their way into the soil through spray drifts, or as wash-off from treated foliage [4]. From the soil, these pesticide residues may get directly vaporized along with the evaporating soil moisture or are leaked into the ground and surface waters through leaching or run-off [5-8]. The situation is more aggravated if a mixture of pesticides is present in the soil because they render the remediation process to be more difficult [9]. The pesticides cause various diseases among the exposed individuals such as cancers of various types and impairment of kidneys and thyroid glands [10]. Moreover, these pesticides have also proved to be detrimental to nontarget, beneficial soil microorganisms. That is why the determination of levels of pesticides in soil, groundwater, and crops has always been the subject of interest [11-14].

Pesticide degradation is an important phenomenon that helps in remediating the contaminated soils and water bodies. It is shown to be assisted by a number of factors such as moisture content of soil, soil texture, and soil mineral contents [9]. The presence of metals in the soil has also recently been shown to affect the degradation of pesticides [15]. These metals either are added to the soil along with pesticides or originate from the long-term application of wastewater and animal manures to agricultural soils $[16,17]$. In fact metals affect the pesticide degradation by catalyzing the photolysis/hydrolysis of pesticides or influencing the activity of microorganisms [18]. Similarly, complexation interactions between pesticides and metals may lead to a decrease in the rate of degradation of pesticides [19].

Tian et al. studied the influence of bimetallic $\mathrm{Ni} / \mathrm{Fe}$ nanoparticles on the degradation of DDT in aqueous solutions at room temperature [20]. Liu et al. observed that coexisting $\mathrm{Cu}$ ions in the soil influence the degradation 
of cypermethrin and cyhalothrin by affecting the activity of microorganisms [21]. Complexation interactions between imazapyr pesticide and metal ions were found to decrease the imazapyr photolysis [22]. It has also been found that selected metal ions having paramagnetic property could inhibit the aquatic photodegradation of some pesticides with humic acids [23].

The present study focuses on tracing the correlation patterns among the levels of coexistent metals and pesticides in the soil. The correlation model thus developed between pesticide and heavy metals will be useful for monitoring the pesticides in soil, due to the measurement of heavy metals being more available. So, the study may provide the basis for the management of soils contaminated with pesticides subsequent to successful monitoring.

\section{Materials and Methods}

2.1. Quality Control and Quality Assurance. High quality Pyrex glassware was used during the present study which was thoroughly cleaned with chromic mixture, 5\% detergent solution, and finally distilled water. All the volumetric apparatus employed for measurements, sample processing, and dilution was calibrated before use. In order to deliver the small volume (i.e., $<1.0 \mathrm{~mL}$ ) of stock standard solutions, pipettes of $1.00 \mathrm{~mL}$ capacity were used.

Double distilled water was used for the preparation of blanks, standards, and reagents. Analytical grade reagents with a $99.99 \%$ certified purity were procured from E-Merck (Germany) and used for quantification. The stock standard solutions of selected metals $(1000 \mathrm{mg} / \mathrm{L})$ as provided by E-Merck (Germany) were utilized for the preparation of working standards after appropriate dilution with DDW. The inconsistencies in measurement likely to arise from the use of highly concentrated stock solutions were avoided by the use of an intermediate working standard of $100 \mathrm{mg} / \mathrm{L}$ concentration. HPLC grade chemicals provided by E-Merck Germany were used for the extraction of pesticides, sample cleanup, and mobile phase formation. The analytical standards of three pesticides were obtained from Riedel-deHaen (Germany). The chances of any photodegradation of reagents were avoided by storing them in the dark.

The levels of selected trace metals, that is, $\mathrm{Co}, \mathrm{Pb}, \mathrm{Cr}, \mathrm{Ni}$, $\mathrm{Cu}$, and $\mathrm{Cd}$, were determined by using HITACHI AAS Z5000 spectrophotometer. The calibration curve method was used to quantify the results. At least six standards were run covering the absorption range of samples. The precision of quantitative results was ensured by analyzing the triplicate samples.

The residues of three selected pesticides, that is, imidacloprid, emamectin, and acetamiprid, were determined by using the HPLC System of Waters 1500. The detector used for the present investigation was Waters-2487, a dual wavelength absorbance detector, designed especially for HPLC applications.

The extracted and cleaned pesticide residue samples were injected into the chromatographic system equipped with $\mathrm{C}$ 8 column at a rate of $1 \mathrm{~mL} / \mathrm{min}$. The eluent used was a $3: 2$ mixture of water and acetonitrile. At the retention times of 4.93 minutes, the signals for imidacloprid, emamectin, and acetamiprid were recorded by UV detector at specified wavelengths of $270 \mathrm{~nm}, 245 \mathrm{~nm}$, and $254 \mathrm{~nm}$, respectively.

2.2. Sampling. For the present investigation, a total of 52 top soil $(1-15 \mathrm{~cm})$ samples were collected from ten different fields of Pakpattan, Pakistan. A $300 \mathrm{~g}$ portion of each of the soil samples was taken in zip mouthed polyethylene bags with the help of soil auger. These samples were properly labeled and immediately transferred to lab, where they were stored at $4^{\circ} \mathrm{C}$ until analysis. The electrical conductivity and $\mathrm{pH}$ of the samples were determined by immersion probe technique while moisture content, chloride, nitrate, and sulphate were determined by appropriate standard methods [24]. All samples were treated and analyzed at the laboratory of Department of Chemistry, Lahore College for Women University, Lahore. In order to get the reference data, the background soil samples were collected from remotely located agricultural soil with sandy loam texture, where no pesticides were used previously. These background soil samples were also processed quite similar to the samples from the fields.

2.3. Description of Study Area. The district Pakpattan is one of the major cotton growing areas in Pakistan. It covers an area of about $3,084 \mathrm{~km}^{2}$ with a population density of 417 persons per sq.km. A highly fertile land and a climate that is most suitable for sustaining the crops are the main features of the area. The city is bounded by river Satluj and Bias that constitute the main source for irrigation. Therefore, $88 \%$ of the area is comprised of cultivated land. Soil texture here varies from silt loam to clay loam and average annual rainfall is $200-300 \mathrm{~mm}$. The temperature ranges from $6.6^{\circ} \mathrm{C}$ in winter to $41.7^{\circ} \mathrm{C}$ during the summer. The main crops grown here include wheat, rice, cotton, maize (corn), and sugar cane. In addition, about 507 agriculture based industrial units are present in the district that include fertilizer, cotton pressing and ginning, oil mills, flour mills, rice mills, poultry feed, textile weaving, and sugar mills. The exports from the area consist principally of cotton, wheat, and oilseeds. To accomplish the present study, a total of fifty-two samples were obtained from cotton growing areas of Pakpattan. The sampling sites location is shown in Figure 1.

2.4. Determination of Physicochemical Parameters. The collected soil samples were ground, homogenized, and subsequently sieved through a brass sieve with pore size of $850 \mu \mathrm{m}$ in accordance with international standards for soil analysis [24]. The water extract of soil samples was prepared by stirring a 1:10 soil-water mixture for five minutes and allowing equilibration for thirty minutes. The filtrate thus obtained was used for the determination of physicochemical parameters such as chlorides and nitrates sulphates [25]. In order to determine the soil bulk density, undisturbed cores of dimensions $0.05 \times 0.072 \mathrm{~m}$ were drawn from 5 to $10 \mathrm{~cm}$ depth of soil [26].

The $\mathrm{pH}$ of all the soil samples was determined by using a Inolab-720, portable $\mathrm{pH}$ meter, precalibrated by using standard buffer solutions of $\mathrm{pH} 4.0,7.0$, and 9.0. The conductivity of water extract of soil samples was determined by using WTW, Inolab-720 conductivity meter. 


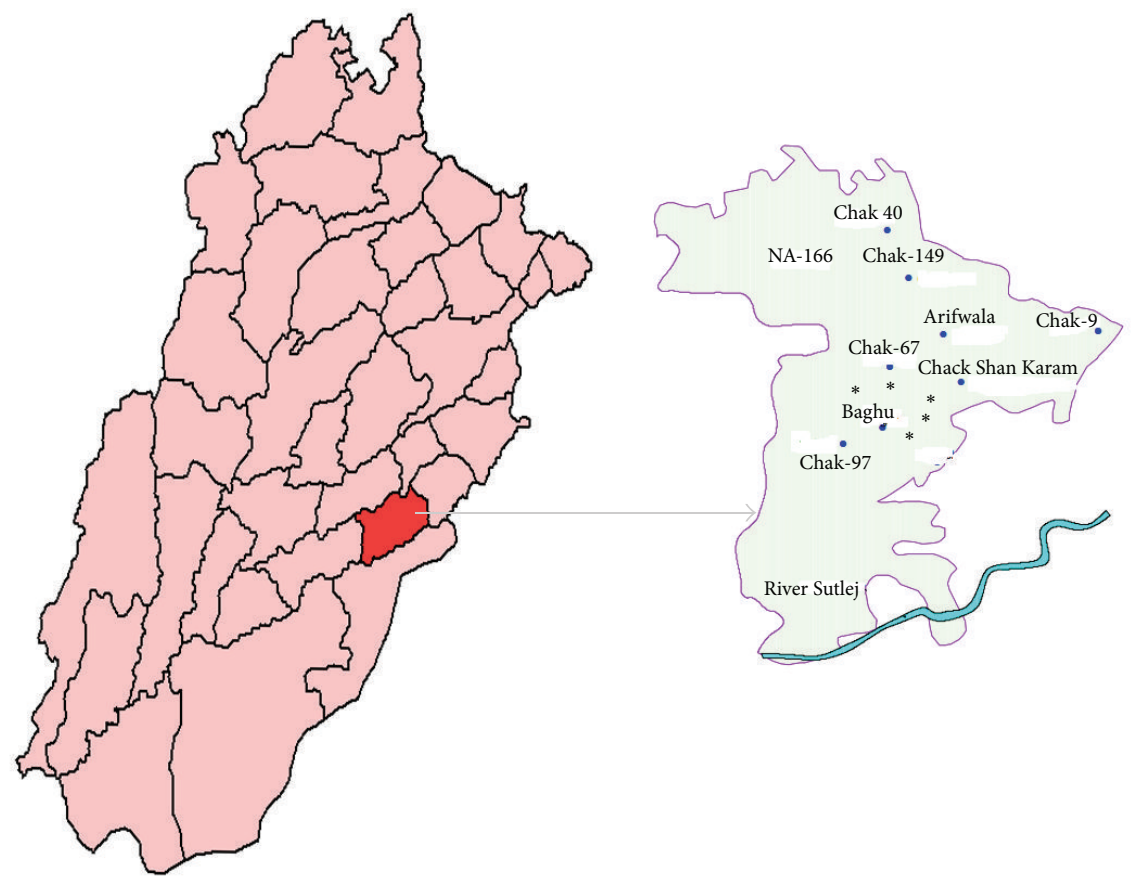

FIGURE 1: Location map of sampling sites*.

The chloride contents of the soil samples were determined gravimetrically by using $\mathrm{AgNO}_{3}$ as precipitant [27]. In order to determine the sulphate ions, a $10.0 \mathrm{~mL}$ portion of water extract of soil samples was stirred for five minutes with $\mathrm{HCl}$ and glycerol solutions along with approximately $0.03 \mathrm{~g}$ of $\mathrm{BaCl}_{2}$. Immediately, after stirring, the solution was poured into a quartz cell with an optical path of $1.0 \mathrm{~cm}$ and the absorbance was measured at $420 \mathrm{~nm}$ on a UV spectrophotometer. A series of calibration standards between concentrations of 0.5 and $5 \mathrm{mg} \mathrm{SO}_{4}{ }^{2-} / \mathrm{L}$ were prepared and used for drawing calibration curve [24].

Nitrate present in the soil samples was determined by using the sodium salicylate method. Here $10.0 \mathrm{~mL}$ portions of water extract of each of the soil samples were evaporated with $1.0 \mathrm{~mL}$ of sodium salicylate and cooled to room temperature. Subsequently $1.0 \mathrm{~mL}$ of concentrated $\mathrm{H}_{2} \mathrm{SO}_{4}$ was added to dehumidify the entire residue and allowed to stand for 10 minutes. It was then quantitatively transferred to a $50 \mathrm{~mL}$ volumetric flask, added with $7.0 \mathrm{~mL}$ of $\mathrm{NaOH}$, and adjusted the volume to $50 \mathrm{~mL}$ with distilled water. After 10 minutes, the absorbance was measured at $410 \mathrm{~nm}$ against the blank prepared in the same way. Calibration curve was constructed by using the standard $\mathrm{KNO}_{3}$ solutions in the concentration range of $2-20 \mathrm{mg} / \mathrm{L}$ [28]. The organic carbon contents of the soil samples were determined by partial oxidation method that involved the titration of soil samples against $1 \mathrm{~N}\left(\mathrm{NH}_{4}\right)_{2} \mathrm{Fe}\left(\mathrm{SO}_{4}\right)_{2} \cdot 6 \mathrm{H}_{2} \mathrm{O}$ solution by using diphenylamine indicator [29].

Pesticide Analysis by HPLC. The residues of selected pesticides, that is, imidacloprid, acetamiprid, and emamectin, were extracted from soil samples by using methanol as solvent. The extraction procedure adopted involved the shaking of the appropriate amount of soil samples with $100 \mathrm{~mL}$ of methanol on an orbital shaker for 30 minutes. The residual cake was extracted twice with $100 \mathrm{~mL}$ methanol. The methanol extracts were combined, filtered, and then concentrated under reduced pressure to dryness at $40^{\circ} \mathrm{C}$.

Sample Cleanup. The contaminated sample extracts cause the loss of detector sensitivity, shorten the life time of column, produce extraneous peaks, and deteriorate peak resolution and column efficiency [27]. Therefore, the extract was cleaned by using a Florasil packed column. Briefly, about $20 \mathrm{~g}$ of Florasil was added to a preconditioned chromatographic column between two layers of anhydrous sodium sulphate (1 to $2 \mathrm{~cm}$ deep). The concentrated extract was loaded onto the top of the column. The column was drained with acetonitrile until the sodium sulphate layer was exposed. It was then eluted with mobile phase at a drip rate of about $5 \mathrm{~mL} / \mathrm{min}$. Mobile phase for HPLC analysis was prepared by mixing $0.01 \%$ of acetic acid and acetonitrile in $60: 40$ ratio. The eluate was concentrated and residue was redissolved in $5 \mathrm{~mL}$ of acetonitrile. This cleaned extract was used for pesticide analysis by HPLC.

2.5. Metal Analysis by AAS. Wet acid digestion method was used for the analysis of metals present in soil samples. Briefly, $1.0 \mathrm{~g}$ portions of air-dried and sieved soil samples were added with $15 \mathrm{~mL}$ of $1: 1$ conc. $\mathrm{HNO}_{3}$ and refluxed without boiling at $95^{\circ} \mathrm{C}$ for about $10-15$ minutes. It was further added with $3 \mathrm{~mL}$ of concentrated $\mathrm{HNO}_{3}$ and heating was continued for about 30 minutes. Subsequently, the contents were cooled to room temperature and added with about $5 \mathrm{~mL}$ of $30 \% \mathrm{H}_{2} \mathrm{O}_{2}$ 
TABLE 1: Analytical parameters for the estimation of selected metals by AAS.

\begin{tabular}{|c|c|c|c|c|c|c|}
\hline Sr. number & Metal & Wavelength (nm) & Lamp current $(\mathrm{mA})$ & Slit width $(\mathrm{nm})$ & Fuel flow rate $(\mathrm{L} / \mathrm{min})$ & Detection limit $(\mathrm{mg} / \mathrm{L})$ \\
\hline 1 & $\mathrm{~Pb}$ & 283.3 & 9.0 & 1.3 & 2.2 & 0.20 \\
\hline 2 & $\mathrm{Cr}$ & 359.3 & 9.0 & 1.3 & 2.8 & 0.05 \\
\hline 3 & Co & 240.7 & 15 & 0.2 & 2.2 & 0.20 \\
\hline 4 & $\mathrm{Cu}$ & 324.8 & 9.0 & 1.3 & 2.2 & 0.02 \\
\hline 5 & $\mathrm{Ni}$ & 232.0 & 12 & 0.2 & 2.2 & 0.10 \\
\hline 6 & $\mathrm{Cd}$ & 228.8 & 9.0 & 1.3 & 2.0 & 0.005 \\
\hline
\end{tabular}

in aliquots. Digestion was continued until effervescence subsided. Then, a $15 \mathrm{~mL}$ portion of concentrated $\mathrm{HCl}$ was added and contents were cooled, filtered through a sintered glass crucible, and finally diluted up to $50 \mathrm{~mL}$ with distilled water [30]. This acid extract was aspirated directly onto AAS for metal estimation under optimum analytical conditions as given in Table 1 .

2.6. Statistical Analysis of Data. The data set obtained for various physicochemical parameters, metals, and pesticide residues in the representative soil samples was treated statistically by both univariate and multivariate statistical analyses. The univariate statistical analysis involved the evaluation of basic statistical parameters like mean, standard deviation, standard error, kurtosis and skewness, and the linear correlation coefficient matrix. Correlation coefficient matrix furnished the correlation patterns among various metal pairs, physicochemical parameters, and pesticides in the soil media. Multiple correlation matrix was also developed in terms of metal-to-pesticide, metal-to-physicochemical parameters, and pesticide-to-physicochemical parameters to determine the dependence of various parameters upon each other. The multivariate statistical analysis in terms of cluster analysis was performed to get an insight into the clustering behavior of various parameters on mass scale by using Statistica software [31].

\section{Results and Discussion}

3.1. Distribution of Various Parameters of Soil Samples. Physical properties of the soil influence the mobility and pathways of nutrients and pollutants within the soil. Similarly, the accumulation of the xenobiotics (foreign chemicals) in the soil is governed by a number of physicochemical parameters of soil such as its $\mathrm{pH}$, conductance, and the amount of inorganic ions $\left(\mathrm{Cl}^{-}, \mathrm{NO}_{3}{ }^{-}, \mathrm{SO}_{4}{ }^{2-}\right.$, etc. $)$. It is therefore necessary to evaluate these physicochemical parameters and determine their mutual relationship so that a sustainable agriculture may be maintained.

The basic statistics for the physicochemical parameters, metal levels, and pesticide concentrations in fifty-two soil samples collected from ten fields of Pakpattan, Pakistan, are enlisted in Table 2. The soil samples were grayish in colour and the texture of all the soil samples was sandy loam. The bulk density of soil samples was found to range from 1.53 to $1.61 \mathrm{Mgm}^{-3}$ with a mean value standing at $1.568 \mathrm{Mgm}^{-3}$. $\mathrm{pH}$, another important parameter for the agricultural soil, was found to be present at narrow range of 7.6-8.5, with a mean value of 8.1. Soils with these $\mathrm{pH}$ values exhibit higher availability of metals such as $\mathrm{Mg}, \mathrm{Ca}$, and $\mathrm{K}$ while some other metals such as $\mathrm{Fe}, \mathrm{Zn}$, and $\mathrm{Cu}$ are less available at this $\mathrm{pH}$ [32]. It is also known that, under alkaline conditions, the adsorption of pesticides takes place to a lesser extent, and thus they degrade easily [33-35].

The organic matter content of soil is regarded as a major factor controlling the sorption, transport, and transformation of pesticides [36]. For the present soil samples, it was found to vary from 1.29 to $11.39 \%$ with a mean value of $4.616 \%$. An organic carbon content of $>5 \%$ may enhance the sorption of pesticides in soil depending on the nature of pesticides and organic matter; this in turn reduces the leaching and transport properties of pesticides [37]. In case of present study, the mean organic carbon content of soils was found below 5\%, but slightly higher than background levels. Thus in these soils, the extent of sorption of pesticides to the soil may not be significant, but this may be evidenced clearly on the basis of a more comprehensive study based on chemometrics.

The ionic strength of these soil samples is represented by a mean conductivity value of $1412 \mu \mathrm{S} / \mathrm{cm}$, signifying that a larger portion of solubilized cations and anions are present in the water extracts of soil samples, which were most likely derived from the fertilizers and manure used to restore the fertility of soil. It was further confirmed by the presence of high concentration of anions such as chloride, nitrate, and sulphate in the soil samples.

The mean chloride, nitrate, and sulphate levels recorded for these soil samples were $12.9,35.01$, and $47.1 \mathrm{mg} / \mathrm{g}$, respectively, with their sample variances of $3.77 \times 10^{7}, 1.178 \times 10^{8}$, and $4.66 \times 10^{8}$, respectively. The order of mean levels of these anions thus remained: $\mathrm{SO}_{4}{ }^{2-}>\mathrm{NO}_{3}{ }^{-}>\mathrm{Cl}^{-}$. Large values for standard deviation projected a large spread of data set around the mean value.

The excessive sulphate concentration in the soil originates from the use of zinc sulphate and urea in addition to decayed vegetable matter, compost, and manure used to normalize the soil $\mathrm{pH}$. The enhanced levels of nitrate in the soil as compared to background soil pointed towards an excessive use of nitrate fertilizers such as nitrates of sodium, potassium, calcium, and ammonium in fields.

The use of pesticides has contributed significantly towards increased agricultural yield, protection of livestock, and the reduction of vector-transmitted diseases, but their impacts on ecosystems and humans have always been focused on by scientific, regulatory, and policy communities [38-40]. Imidacloprid, acetamiprid, and emamectin were 


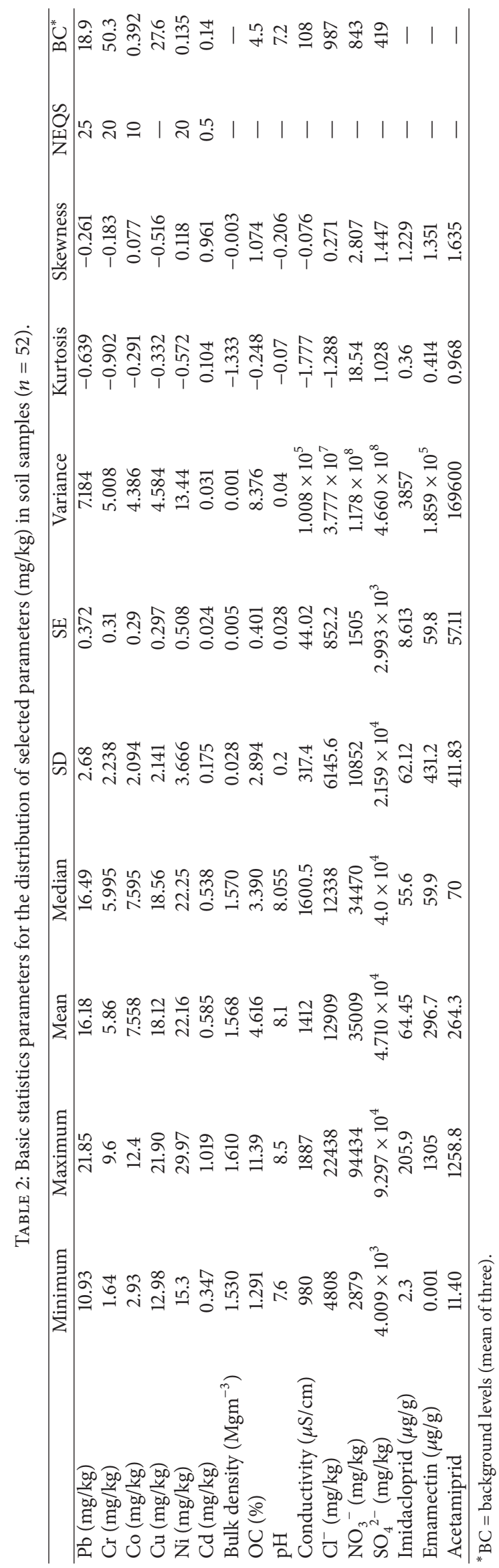



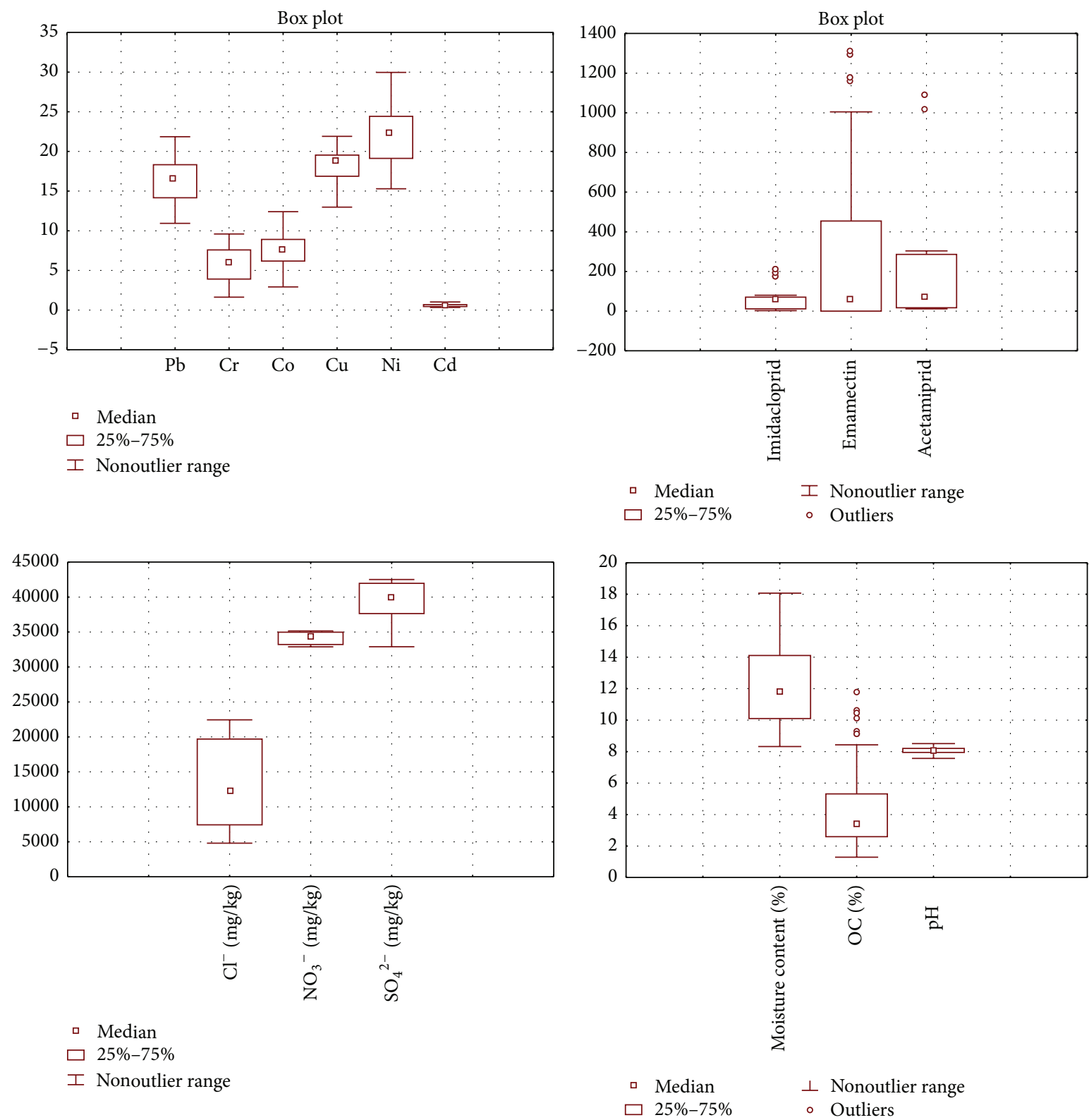

FIGURE 2: Box and Whisker plots for the distribution of various parameters in soil.

the pesticides that are being applied to the cotton crops of Pakpattan intermittently. That is why these pesticides were included in the study. The data recorded a great variability in the concentrations of imidacloprid that was present at a minimum value of $2.3 \mu \mathrm{g} / \mathrm{g}$ and a maximum value of $205.9 \mu \mathrm{g} / \mathrm{g}$ with a mean value standing at $64.45 \mu \mathrm{g} / \mathrm{g}$. This large variation in the recorded values reflected the differences in the extent of exposure of soil to the pesticides. Emamectin was present in these samples at mean levels of $296.7 \mu \mathrm{g} / \mathrm{g}$, while the mean levels for acetamiprid were $264.3 \mu \mathrm{g} / \mathrm{g}$. The large variation between the mean and median values depicted the nonnormal distribution of the data which was also reflected by high SD, skewness, and kurtosis values. The distribution of these pesticides has also been depicted in Box plots (Figure 2).
The data for the descriptive statistics of selected metals (i.e., $\mathrm{Pb}, \mathrm{Cr}, \mathrm{Co}, \mathrm{Cu}, \mathrm{Ni}$, and $\mathrm{Cd}$, Table 2, Figure 2) showed that nickel in these samples was present at highest mean concentration of $22.16 \mathrm{mg} / \mathrm{kg}$. The major source of $\mathrm{Ni}$ in these soils may be the Ni plating industry located nearby. $\mathrm{Ni}$ was followed by $\mathrm{Cu}$ that exhibited a mean concentration of $18.12 \mathrm{mg} / \mathrm{kg}$. The minimum and maximum concentrations recorded for $\mathrm{Cu}$ were 12.98 and $21.90 \mathrm{mg} / \mathrm{kg}$, respectively. Copper is required for various biochemical processes in plants; thus it is an essential trace element, but its enhanced concentrations are hazardous for human populations [41].

Lead was another heavy metal that was present in these samples at appreciable maximum concentration of $16.18 \mathrm{mg} / \mathrm{kg}$. Over the past few decades, the vehicular emissions from leaded gasoline have been overcome due to ban 
on leaded gasoline; thus the source of this lead in soil was traced in various fungicides and pesticides like lead arsenate and so forth that are used at various stages of crop production [2]. Cadmium was the metal that was present at trace level of $0.585 \mathrm{mg} / \mathrm{kg}$. Chromium, another hazardous metal, was found to be present at a mean level of $5.86 \mathrm{mg} / \mathrm{kg}$. Its maximum concentration was recorded to be $9.6 \mathrm{mg} / \mathrm{kg}$ which is quite higher than the limit set for agricultural soils. This chromium not only is hazardous for soil biota but may also contaminate the food chain through uptake and accumulation by plants; furthermore depending on the soil conditions like $\mathrm{pH}$, it may become soluble and thus enter the groundwater, the only source of drinking water in the area.

The mean levels recorded for Co were $7.558 \mathrm{mg} / \mathrm{kg}$. The order of the mean concentrations of metals in the soil samples remained: $\mathrm{Ni}>\mathrm{Cu}>\mathrm{Pb}>\mathrm{Co}>\mathrm{Cr}>\mathrm{Cd}$. The symmetry parameters for the data, that is, standard deviation, skewness, and kurtosis, are also listed in Table 2.

A comparison of mean metal levels with National Environmental Quality Standards (NEQS) is also depicted in Table 2. The average $\mathrm{Pb}$ concentration in soil samples was found to be $16.18 \mathrm{mg} / \mathrm{kg}$ against the standard value of $25 \mathrm{mg} / \mathrm{kg}$. The estimated value of lead in soil samples was lower than standard value which indicated that soil $\mathrm{Pb}$ was below the contamination level and would not pose a significant threat of contaminating the food chain. Moreover, $\mathrm{Pb}$ uptake by plants depends upon soil $\mathrm{pH}$; that is, at higher $\mathrm{pH}$, lead becomes immobilized. It is also known that, due to small transfer factor, $\mathrm{Pb}$ is not taken up by plants below a concentration of $300 \mu \mathrm{g} / \mathrm{g}$ in soil, and if taken up, it would accumulate in leaves rather than the fruit $[42,43]$.

The mean level of Cr recorded in soil was $5.86 \mathrm{mg} / \mathrm{kg}$. This value is approximately four times less than standard value of $20 \mathrm{mg} / \mathrm{kg}$ (NEQS). Co was present in the soil samples at the mean level of $7.558 \mathrm{mg} / \mathrm{kg}$ which is also less than standard value of $10 \mathrm{mg} / \mathrm{kg}$. The mean concentration of $\mathrm{Cu}$ in soil samples was found to be $18.12 \mathrm{mg} / \mathrm{kg}$. Ni was present in soil samples at the mean level of $22.16 \mathrm{mg} / \mathrm{kg}$ slightly higher than the recommended standard value of $20 \mathrm{mg} / \mathrm{kg}$.

The mean concentration of $\mathrm{Cd}$ was found to be $0.585 \mathrm{mg} / \mathrm{kg}$, a value slightly exceeding the standard value of $0.5 \mathrm{mg} / \mathrm{kg}$. In fact, fertilizers are added regularly to soils to replenish $\mathrm{N}, \mathrm{K}$, and $\mathrm{P}$ for good crop growth. These compounds contain trace amounts of $\mathrm{Cd}$ as impurities, which, after continued application, are significantly increased in the soil [44]. Overall, it was concluded that $\mathrm{Pb}, \mathrm{Cr}, \mathrm{Cu}$, and Co were present in tolerable range in the soil samples but $\mathrm{Ni}$ and $\mathrm{Cd}$ surpassed the standard value but not to greater extents. Thus although the selected metals do not pose any threat to the environment at their present levels, but with the passage of time, the unwise use of agricultural activities may lead to a large buildup of metals in the soil that may endanger the environment as well as human health.

3.2. Correlation Coefficient Matrices of Various Parameters in the Soil. Table 3 depicted the correlation coefficient matrix for the studied physicochemical parameters, pesticides, and metal levels in the soil samples collected from the agricultural fields. The $r$-values were found to be significant at \pm 0.231 $(p<0.05)$. The data was characterized by both negative and positive correlations between various pairs of parameters. The data was nonnormally distributed and also the anthropogenic activities led to a change in the natural concentration of some of the parameters. Thus all the observed correlations were not high. For the physicochemical parameters, the most significant positive correlation was observed between electrical conductivity and chloride levels with an $r$-value 0.292 , evidencing that, in about $29.2 \%$ cases, the electrical conductivity of soil was observed to be increased with an increase in chloride content and vice versa. Similarly, a strong positive correlation was observed between $\mathrm{pH}$ and sulphate with $r$-values of 0.235 . Organic carbon content of soil was found to be positively correlated with nitrate levels but this correlation was not significant.

The correlation coefficient matrix for the levels of selected metals in the collected soil samples depicted the strongest positive correlation between $\mathrm{Cr}$ and $\mathrm{Ni}$ at an $r$-value of 0.460 , thereby showing that in $46.0 \%$ cases the concentration of $\mathrm{Cr}$ went in parallel with concentration of $\mathrm{Ni}$, thus sharing a similar origin in the soil matrix. The next strongest positive correlation was observed between $\mathrm{Ni}$ and $\mathrm{Cu}$ pair (0.431). The other metal pair that was significantly positively correlated included $\mathrm{Cr}$-Co ( $r$-value 0.343$)$. $\mathrm{Cr}, \mathrm{Ni}$, and $\mathrm{Cu}$ were found to be strongly negatively correlated with $\mathrm{Cd}(r$-values of $-0.407,-0.430$, and -0.375 , resp.) depicting an increase in concentration of one metal with a decrease in concentration of other metals.

No significant, positive, or negative correlation was observed among the selected pesticides depicting that the sources of pesticides in the soil were not the same. This is also due to the fact that different pesticides are applied to the crops at different stages of crop production. Thus they enter the soil at different periods of time. The data corresponding to the correlation coefficient matrix for the physicochemical parameters and the various metals depicted only few significant positive/negative correlations. $\mathrm{Ni}$ of the soil exhibited the strongest positive correlation with its conductivity with $r$-value of 0.342 . $\mathrm{Cu}$ was also significantly positively correlated with the conductivity ( $r$-value of 0.286). Cd and electrical conductivity were significantly negatively correlated. Another significant negative correlation was observed between $\mathrm{Cr}$ and nitrate level of soil solution. The other correlations were too naïve to be discussed.

The correlation coefficient matrix for the pesticidesto-physicochemical parameters depicted a significant negative correlation between soil organic carbon content and emamectin thereby evidencing the influence of soil organic carbon on the sorption of emamectin. Soil EC values were also found to be negatively correlated with imidacloprid and emamectin.

Numerous metals are known to possess good catalysis ability, and they may affect the behavior of coexisting pesticides in the soil. Thus the most important segment of the present investigation was to study the correlations among the selected pesticides and various metal levels. The data depicted a strong positive correlation between acetamiprid and $\mathrm{Cu}$ with $r$-value of 0.239 . A strong positive correlation pointed towards an increase in the concentration of acetamiprid 


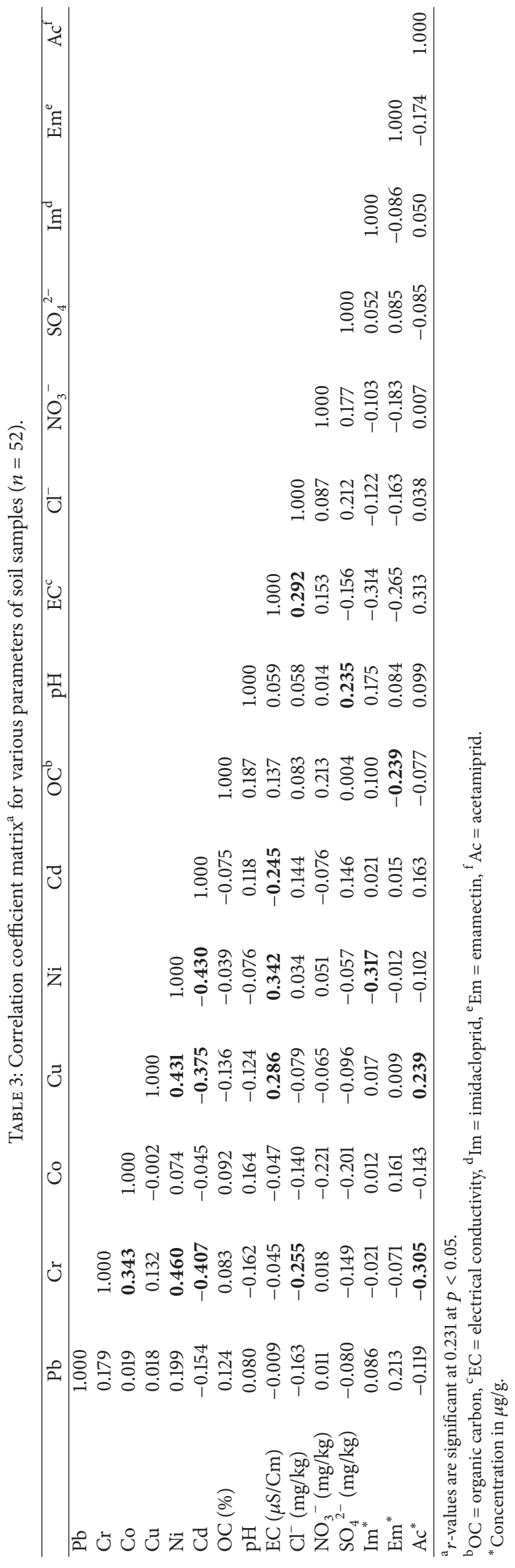




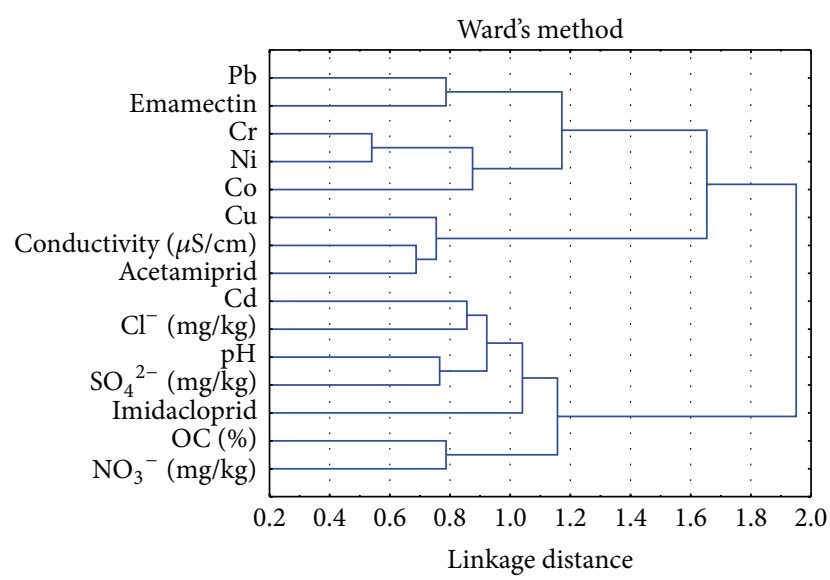

FIGURE 3: Cluster analysis for the determination of various parameters.

with the presence of greater concentration of copper in the soil. On the other hand, imidacloprid in soil was found to be negatively correlated with $\mathrm{Ni}$ of soil ( $r$-value of -0.317$)$. Similarly, a significant negative correlation was observed between $\mathrm{Cr}$ and acetamiprid ( $r$-value, -0.305$)$. Thus it was evidenced that $\mathrm{Cu}$ stabilizes acetamiprid while $\mathrm{Cr}$ and $\mathrm{Ni}$ facilitate the degradation of acetamiprid and imidacloprid in the soil [45].

Similar results have been reported for pyrethroid pesticides, whose degradation was shown to be inhibited by the presence of copper ions. Ellis et al. reported that metals like $\mathrm{Cu}$ present in soil may react with the sulfhydryl group of enzymes and inhibit their activity. Thus the pesticides become more persistent, thereby leading to an increase in their concentration with time $[21,46]$.

\subsection{Cluster Analysis of Various Parameters in the Soil Sam-} ples. Cluster analysis has proved to be a milestone toward the source apportionment studies of various pollutants like metals and pesticides in the soil and other media $[47,48]$. In this analysis (Figure 3), linkage distance is used as the measure of degree of closeness and hence relation among the various parameters [49]. A number of clusters were formed within a significant linkage distance. The strongest cluster was observed between $\mathrm{Cr}$ and $\mathrm{Ni}$ evidencing that high $\mathrm{Cr}$ content of the soil was associated with the enhanced $\mathrm{Ni}$ levels. These two metals were further associated with Co to form a second cluster within linkage distance of 1.0. The most important cluster of the study was observed between acetamiprid and conductivity that was further associated with $\mathrm{Cu}$. It evidenced that $\mathrm{Cu}$ present in the soil may cause the persistence of acetamiprid whose concentration increases with time. Similarly, emamectin was closely associated with Pd.

Cluster analysis revealed a close association between sulphate and $\mathrm{pH}$, which formed a primary cluster within linkage distance of 0.6. This primary cluster was further associated with $\mathrm{Cd}_{\text {and }} \mathrm{Cl}^{-}$within linkage distance of 1.0 on one side and with imidacloprid in the soil on the other side.
The organic carbon of soil was associated with nitrate within a linkage distance of 0.8 and this factor was further associated with previous cluster.

Overall, the study revealed that frequently used pesticides, that is, imidacloprid, emamectin, and acetamiprid, were present in the soil of cotton fields and were influenced by factors such as soil $\mathrm{pH}$ and organic carbon. The study also furnished correlations among pesticides and metals in the soil. It was shown that presence of certain metals such as $\mathrm{Ni}$ caused the decreased levels of imidacloprid. Similarly, $\mathrm{Cr}$ enhanced the degradation of acetamiprid and $\mathrm{Cu}$ caused the persistence of this pesticide in the soil.

\section{Conclusions}

The soil samples collected from the cotton growing area of Pakpattan, Pakistan, were slightly basic in nature. The mean $\mathrm{Pb}, \mathrm{Cr}, \mathrm{Co}$, and $\mathrm{Cu}$ levels were below NEQS while the levels of $\mathrm{Ni}$ and $\mathrm{Cd}$ were slightly above NEQS. These levels may be tolerated by following precautionary measures in agricultural activities. Among the pesticides, emamectin exhibited a high persistence in the soil that was closely associated with soil $\mathrm{Cu}$ content. It was also found that $\mathrm{Cu}$ stabilizes acetamiprid while $\mathrm{Cr}$ and $\mathrm{Ni}$ facilitate the degradation of acetamiprid and imidacloprid. Thus the study provides basis for the risk assessment studies that are quite necessary to manage the contaminated sites in a cost effective manner while preserving the public and ecosystem health. It also provides a management strategy for remediation of contaminated soil; that is, adding traces of $\mathrm{Ni}$ and $\mathrm{Cr}$ in the soil may help in the degradation of frequently used acetamiprid and imidacloprid.

\section{Conflict of Interests}

The authors declare no conflict of interests.

\section{References}

[1] R. A. Cloyd and J. A. Bethke, "Impact of neonicotinoid insecticides on natural enemies in greenhouse and interiorscape environments," Pest Management Science, vol. 67, no. 1, pp. 3-9, 2011.

[2] P. Khaliq, L. A. Hashmi, and M. H. Qazi, "Agriculture and environment," Progress Farming, vol. 15, pp. 16-23, 1995.

[3] H. Shiraishi, F. Pula, A. Otsuki, and T. Iwakuma, "Behaviour of pesticides in Lake Kasumugaura, Japan," Science of the Total Environment, vol. 72, pp. 29-42, 1988.

[4] R. Rial Otero, B. Cancho Grande, M. Arias Estévez, E. López Periago, and J. Simal Gándara, "Procedure for the measurement of soil inputs of plant-protection agents washed off through vineyard canopy by rainfall," Journal of Agricultural and Food Chemistry, vol. 51, no. 17, pp. 5041-5046, 2003.

[5] H. M. G. van der Werf, "Assessing the impact of pesticides on the environment," Agriculture, Ecosystems and Environment, vol. 60, no. 2-3, pp. 81-96, 1996.

[6] G. W. vanLoon and S. J. Duffy, Environmental Chemistry: A Global Perspective, Oxford University Press, Oxford, UK, 2nd edition, 2005. 
[7] P. K. Goel, Water Pollution (Causes, Effects and Control), New Age International (P), New Delhi, India, 2nd edition, 2006.

[8] M. Arias-Estévez, E. López-Periago, E. Martínez-Carballo, J. Simal-Gándara, J.-C. Mejuto, and L. García-Río, “The mobility and degradation of pesticides in soils and the pollution of groundwater resources," Agriculture, Ecosystems \& Environment, vol. 123, no. 4, pp. 247-260, 2008.

[9] P. J. Shea, T. A. Machacek, and S. D. Comfort, "Accelerated remediation of pesticide-contaminated soil with zerovalent iron," Environmental Pollution, vol. 132, no. 2, pp. 183-188, 2004.

[10] A. Isaiah and M. Paul, "Synergistic effect of chemical pesticides on commonly grown vegetables in Northern India," Epidemiology, vol. 18, p. S86, 2007.

[11] J. Fenoll, P. Hellín, C. Marín, C. M. Martínez, and A. P. Flores, "Multiresidue analysis of pesticides in soil by gas chromatography with nitrogen-phosphorus detection and gas chromatography mass spectrometry," Journal of Agricultural and Food Chemistry, vol. 53, no. 20, pp. 7661-7666, 2005.

[12] S. Seccia, P. Fidente, D. Montesano, and P. Morrica, "Determination of neonicotinoid insecticides residues in bovine milk samples by solid-phase extraction clean-up and liquid chromatography with diode-array detection," Journal of Chromatography A, vol. 1214, no. 1-2, pp. 115-120, 2008.

[13] S. M. Dem, J. M. Cobb, and D. E. Mullins, "Pesticide residues in soil and water from four cotton growing areas of Mali, West Africa," Journal of Agricultural, Food \& Environmental Sciences, vol. 1, no. 1, pp. 1-12, 2007.

[14] M. W. Aktar, M. Paramasivam, D. Sengupta, S. Purkait, M. Ganguly, and S. Banerjee, "Impact assessment of pesticide residues in fish of Ganga river around Kolkata in West Bengal," Environmental Monitoring and Assessment, vol. 157, no. 1-4, pp. 97-104, 2009.

[15] T. R. Sandrin and R. M. Maier, "Impact of metals on the biodegradation of organic pollutants," Environmental Health Perspectives, vol. 111, no. 8, pp. 1093-1101, 2003.

[16] S. Khan, Q. Cao, Y. M. Zheng, Y. Z. Huang, and Y. G. Zhu, "Health risks of heavy metals in contaminated soils and food crops irrigated with wastewater in Beijing, China," Environmental Pollution, vol. 152, no. 3, pp. 686-692, 2008.

[17] M.-K. Zhang, Z.-Y. Liu, and H. Wang, "Use of single extraction methods to predict bioavailability of heavy metals in polluted soils to rice," Communications in Soil Science \& Plant Analysis, vol. 41, no. 7, pp. 820-831, 2010.

[18] Y. P. Wang, J. Y. Shi, H. Wang, Q. Lin, X. C. Chen, and Y. X. Chen, "The influence of soil heavy metals pollution on soil microbial biomass, enzyme activity, and community composition near a copper smelter," Ecotoxicology \& Environmental Safety, vol. 67, no. 1, pp. 75-81, 2007.

[19] A. A. Helal, D. M. Imam, S. M. Khalifa, and H. F. Aly, "Interaction of pesticides with humic compounds and their metal complexes," Radiochemistry, vol. 48, no. 4, pp. 419-425, 2006.

[20] H. Tian, J. Li, Z. Mu, L. Li, and Z. Hao, "Effect of pH on DDT degradation in aqueous solution using bimetallic Ni/Fe nanoparticles," Separation \& Purification Technology, vol. 66, no. 1, pp. 84-89, 2009.

[21] T.-F. Liu, C. Sun, N. Ta, J. Hong, S.-G. Yang, and C.-X. Chen, "Effect of copper on the degradation of pesticides cypermethrin and cyhalothrin," Journal of Environmental Sciences, vol. 19, no. 10, pp. 1235-1238, 2007.

[22] E. Quivet, R. Faure, J. Georges, J.-O. Païssé, and P. Lantéri, "Influence of metal salts on the photodegradation of imazapyr, an imidazolinone pesticide," Pest Management Science, vol. 62, no. 5, pp. 407-413, 2006.

[23] M. Kamiya and K. Kameyama, "Effects of selected metal ions on photodegradation of organophosphorus pesticides sensitized by humic acids," Chemosphere, vol. 45, no. 3, pp. 231-235, 2001.

[24] M. Radojevic and V. N. Bashkin, Practical Environmental Analysis, Royal Society of Chemistry, Cambridge, UK, 1999.

[25] S. R. Tariq, M. H. Shah, N. Shaheen, A. Khalique, S. Manzoor, and M. Jaffar, "Multivariate analysis of selected metals in tannery effluents and related soil," Journal of Hazardous Materials, vol. 122, no. 1-2, pp. 17-22, 2005.

[26] G. R. Blake and K. H. Hartge, "Bulk and particle density," in Methods of Soil Analysis. Part 1, pp. 363-382, Soil Science Society of America, Madison, Wis, USA, 1986.

[27] P. Patnaik, Handbook of Environmental Analysis, Chemical Pollutants in Air, Water, Soil and Solid Wastes, CRC Lewis, Boca Raton, Fla, USA, 1997.

[28] A. Bartošová, A. Michalíková, M. Sirotiak, and M. Soldán, "Comparison of two spectrophotometric techniques for nutrients analyses in water samples," Research Papers Faculty of Materials Science and Technology Slovak University of Technology, vol. 20, no. 32, pp. 8-19, 2013.

[29] H. Spiegel, E. Filcheva, P. Hegymegi, A. Gal, and F. G. A. Verheijen, "Review and comparison of methods used for soil organic carbon determination, part 2: laboratory study," Soil Science Agrochemistry and Ecology, vol. 41, no. 4, pp. 19-25, 2007.

[30] K. H. Tan, Soil Sampling, Preparation and Analysis, CRC Press, Taylor \& Francis Group, Boca Raton, Fla, USA, 2nd edition, 2005.

[31] StatSoft Inc, STATISTICA for Windows (Computer Program Manual), StatSoft, Tulsa, Okla, USA, 1999.

[32] USDA, Soil Quality Indicator pH, Natural Resources Conservation Service, 1998.

[33] G. E. Lailach, T. D. Thompson, and G. W. Brindley, "Absorption of pyrimidines, purines, and nucleosides by $\mathrm{Co}^{-}, \mathrm{Ni}-, \mathrm{Cu}-$, and $\mathrm{Fe}(\mathrm{III})-$ Montmorillonite (Clay-Organic Studies XIII)," Clays and Clay Minerals, vol. 16, no. 4, pp. 295-301, 1968.

[34] R. G. Nash, W. G. Harris, and C. C. Lewis, "Soil pH and metallic amendment effects on DDT conversion to DDE," Journal of Environmental Quality, vol. 2, no. 3, pp. 390-394, 1973.

[35] J. G. Konrad and G. Chesters, "Degradation in soils of ciodum, an organophosphate insecticide," Journal of Agricultural and Food Chemistry, vol. 17, no. 2, pp. 226-230, 1969.

[36] A. Albarrán, R. Celis, M. C. Hermosín, A. López-Piñeiro, and J. Cornejo, "Behavior of simazine in soil amended with the final residue of the olive-oil extraction process," Chemosphere, vol. 54, no. 6, pp. 717-724, 2004.

[37] J. Dec and J.-M. Bollag, "Determination of covalent and noncovalent binding interactions between xenobiotic chemicals and soil," Soil Science, vol. 162, no. 12, pp. 858-874, 1997.

[38] A. Nawab, A. Aleem, and A. Malik, "Determination of organochlorine pesticides in agricultural soil with special reference to $\gamma$ - $\mathrm{HCH}$ degradation by Pseudomonas strains," Bioresource Technology, vol. 88, no. 1, pp. 41-46, 2003.

[39] M. Bavcon, P. Trebše, and L. Zupančič-Kralj, "Investigations of the determination and transformations of diazinon and malathion under environmental conditions using gas chromatography coupled with a flame ionisation detector," Chemosphere, vol. 50, no. 5, pp. 595-601, 2003.

[40] S. A. Sassman, L. S. Lee, M. Bischoff, and R. F. Turco, "Assessing $N, N^{\prime}$-dibutylurea (DBU) formation in soils after application of 
n-butylisocyanate and benlate fungicides," Journal of Agricultural and Food Chemistry, vol. 52, no. 4, pp. 747-754, 2004.

[41] E. R. Mouta, M. R. Soares, and J. C. Casagrande, "Copper adsorption as a function of solution parameters of variable charge soils," Journal of the Brazilian Chemical Society, vol. 19, no. 5, pp. 996-1009, 2008.

[42] M. Arshad, J. Silvestre, E. Pinelli et al., "A field study of lead phytoextraction by various scented Pelargonium cultivars," Chemosphere, vol. 71, no. 11, pp. 2187-2192, 2008.

[43] G. Uzu, S. Sobanska, Y. Aliouane, P. Pradere, and C. Dumat, "Study of lead phytoavailability for atmospheric industrial micronic and sub-micronic particles in relation with lead speciation," Environmental Pollution, vol. 157, no. 4, pp. 11781185, 2009.

[44] L. H. P. Jones and S. C. Jarvis, "The fate of heavy metals," in The Chemistry of Soil Processes, D. J. Green and M. H. B. Hayes, Eds., p. 593, John Wiley \& Sons, New York, NY, USA, 1981.

[45] S. R. Tariq, M. H. Shah, N. Shaheen, A. Khalique, S. Manzoor, and M. Jaffar, "Multivariate analysis of trace metal levels in tannery effluents in relation to soil and water: a case study from Peshawar, Pakistan," Journal of Environmental Management, vol. 79, no. 1, pp. 20-29, 2006.

[46] R. J. Ellis, B. Neish, M. W. Trett et al., "Comparison of microbial and meiofaunal community analyses for determining impact of heavy metal contamination," Journal of Microbiological Methods, vol. 45, no. 3, pp. 171-185, 2001.

[47] S. R. Tariq, F. Iqbal, and A. Ijaz, "Assessment and multivariate analysis of metals in surgical instrument industry affected top soils and groundwater for future reclamation," International Journal of Environment and Pollution, vol. 1, pp. 54-71, 2013.

[48] S. R. Tariq and N. Rashid, "Multivariate analysis of metal levels in paddy soil, rice plants, and rice grains: a case study from Shakargarh, Pakistan," Journal of Chemistry, vol. 2013, Article ID 539251, 10 pages, 2013.

[49] B. S. Everitt, S. Landau, and M. Leese, Cluster Analysis, Arnold, 4th edition, 2001. 


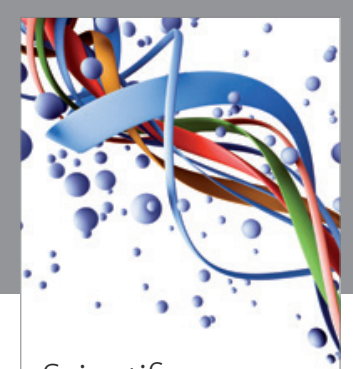

Scientifica
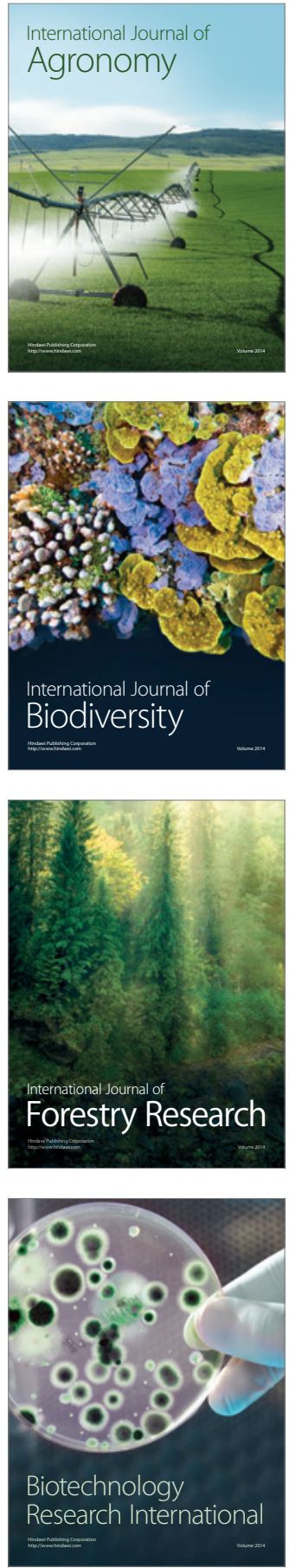
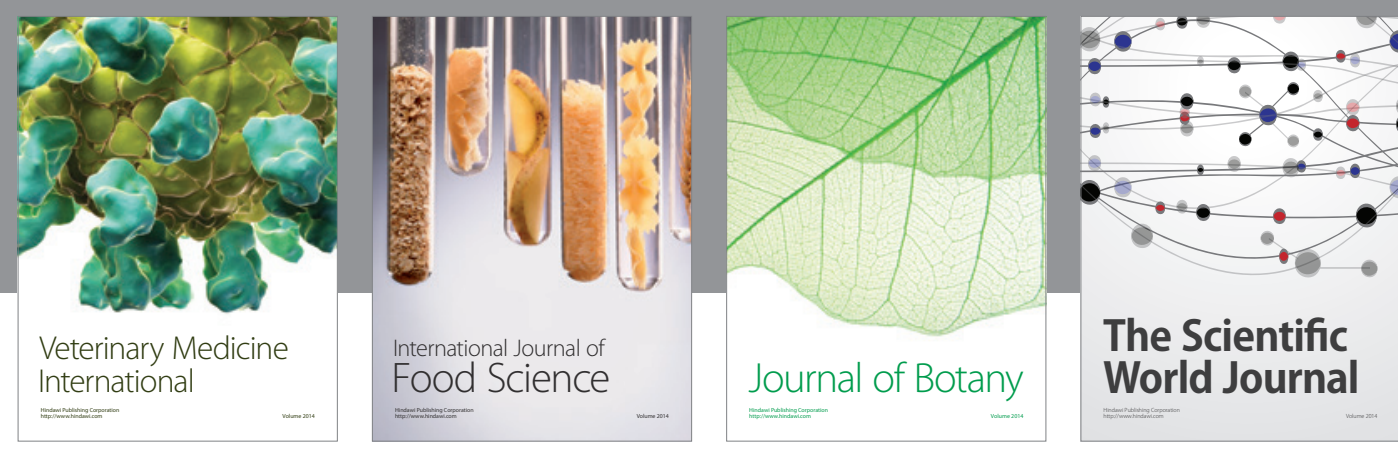

The Scientific

\section{World Journal}

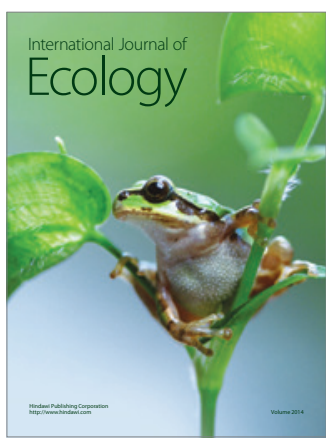

\section{Hindawi}

Submit your manuscripts at

http://www.hindawi.com
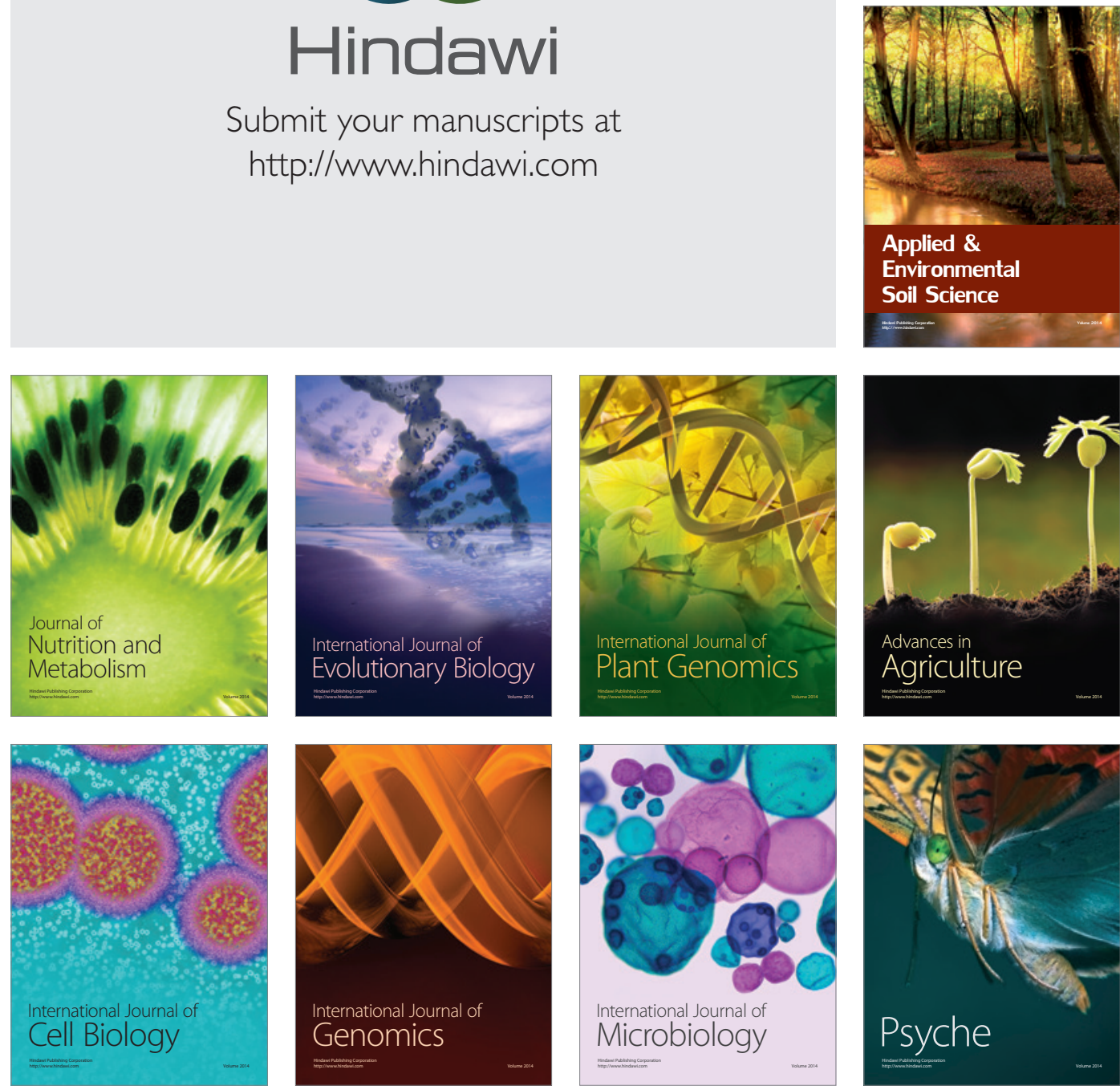
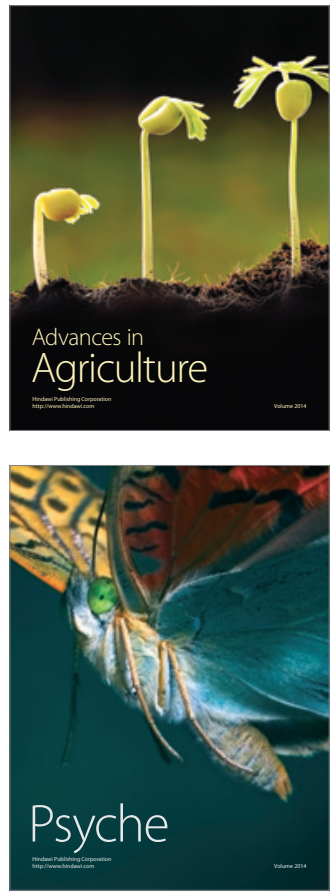